\title{
EDITORIAL
}

\section{Evolutionary psychiatry and the triune brain ${ }^{1}$}

Some physicians are concerned that, because of the present emphasis on molecular and genetic biology and the Paracelsan drive to find a chemical to cure every condition, there is a tendency to treat patients as though they could be manipulated impersonally like machines. They point out that, fruitful as developments in chemotherapy have been, it is naive to believe that anything as complicated as the human brain can be made to dance to any tune by the administration of a single drug or combination of drugs.

Evolutionary psychiatry provides counteractive leaven for reductionistic views inherent in the molecular approach. Psychiatry means, literally, 'mind healing'. Evolutionary psychiatry would therefore apply to potentially salutary insights, derived from a better understanding of how the psychencephalon (MacLean, 1982a) has evolved and how it functions. Starting with the subjective self as its province (its territory), the domain of evolutionary psychiatry encompasses both the microscopic and macroscopic aspects of all the underlying phenomena as they seem to unfold in past-present-future and relate to the cosmos.

In a provocative essay on 'Evolution and tinkering', Jacob (1977) has provided a relevant commentary: 'If molecular biology, which presents a strong reductionist attitude, yielded such a successful analysis of heredity, it was mainly because, at every step, the analysis was carried out simultaneously at the level of the molecules and at the level of ...the bacterial cell." "And it seems likely', he continues, 'that such a convergence of analysis will play an important role in the study of human beings and their societies.'

Jacob (1977) emphasizes the molecular commonalities in animals and the similarities with respect to genetic coding, enzymatic reactions, and so forth. Commenting on the value of evolutionary studies, Darlington (1978) has said: 'Viruses and bacteria are not the precise ancestors of our nuclear and cellular organisms, but they show us how our ancestors must have worked....' Not only are all vertebrates composed of similar cellular types, but they also show many striking commonalities of complex cellular assemblies constituting various organs of the body. Nowhere is the uniformity of vastly complex assemblies more striking than in the cerebral evolution of vertebrates, both as it applies to similarities within classes and to certain commonalities across classes. Such considerations provide the rationale for evolutionary psychiatry and make it inter alia imperative to conduct comparative neurobehavioural studies in an attempt to identify commonalities and differences in the way animals derive information and behave.

Comparative neuroanatomical findings, together with studies of ontogeny, phylogeny, and paleontology, indicate that the human forebrain has evolved and expanded to its great size, while retaining commonalities of three neural assemblies that reflect an ancestral relationship to reptiles, early mammals, and late mammals. Radically different in their chemistry and structure, and in an evolutionary sense aeons apart, the three assemblies constitute an amalgamation of three brains in one, a triune brain (MacLean, 1970, 1973).

In terrestrial vertebrates the forebrain contained in the cerebral hemispheres is essential for giving direction to the activities of the rest of the nervous system which might be regarded as the neural chassis. In such vehicular terms it was as though the cerebral hemispheres constituting the psychencephalon had gradually acquired a complement of three drivers or, as stated in computer language, three central processing assemblies. In the case of human beings there is the major complication for intercommunication that the two 'older' assemblies are not 'wired' and 'programmed' for the transmission of symbolic language.

\footnotetext{
1 Address for correspondence: Dr Paul D. MacLean, P.O. Box 289, Poolesville, MD 20837, USA.
} 
In reptiles, birds and mammals histochemical methods (particularly those demonstrating acetylcholinesterase and dopamine) have been invaluable in identifying corresponding structures of the protoreptilian forebrain. Commonly known as basal ganglia, they include the olfactost 'atum (olfactory tubercle and nucleus accumbens) and structures defined as part of the corpus striatum (caudate nucleus, putamen, globus pallidus, and satellite collections of gray matter). Comparatively speaking, I refer to them as the reptilian complex (R-complex) (MacLean, 1975).

The part of the forebrain identified with early mammals corresponds to the so-called limbic system which comprises the cortex of the great limbic lobe of Broca and structures of the brainstem with which it has primary connections (MacLean, 1952). In reptiles and birds pallial areas with similarities to limbic cortex are rudimentary and are only partially represented. The 'neomammalian brain' consists of the neocortex and structures of the brainstem with which it is primarily connected. (Some anatomists regard the subcortical ganglionic masses in the dorsal ventricular ridge of reptiles and birds as neocortex.)

In our comparative neurobehavioural studies we have focused on the question of the part played by the R-complex and limbic system in basic, species-typical behaviour, including 'prosematic' (non-verbal) communication (MacLean, 1975). Unfortunately, for comparative work no existing reptiles are directly in line with the mammal-like reptiles (therapsids) that are regarded as ancestral to mammals. Since paleontologists have noted a skeletal resemblance between primitive mammallike reptiles and lizards, we have used the latter animals in our comparative studies (MacLean, 1982a).

The distinctive features of the behavioural profile of an animal might be likened to the peaks and subpeaks of a mountain range seen from a distance. When so viewed, the behavioural profile divides into two main ranges. In one range are all the forms of behaviour that enter into an animal's daily master routine and subroutines. In the other range are four main peaks with subpeaks representing four main forms of behaviour used in social communication and referred to in lizards as signature displays, territorial displays, courtship displays, and submissive displays. In animals as diverse as lizards and monkeys we have found that the R-complex appears to be basically implicated in the evocation of displays (MacLean, 1978, 1980; Greenberg et al. 1979). In another set of studies it was found that rodents developing from the time of birth without the neocortex, but retaining the R-complex and the limbic system, engaged in every recognized form of rodent-typical behaviour involved in the daily routine and in communication (Murphy et al. 1981).

The three forms of behaviour that most clearly distinguish the evolutionary transition from reptiles to mammals are: (1) nursing in conjunction with maternal care, (2) audiovocal communication for maintaining maternal-offspring contact, and (3) play. The so-called separation call (isolation call) is probably the most primitive and basic mammalian vocalization, serving originally to maintain maternal-offspring contact and then, later on, contact among members of a group. Contrary to most interpretations of play, I would suggest that it serves originally to promote harmony in the nest and then, later in life, group affiliation (MacLean, 1982a, b). It is now becoming apparent that the thalamocingulate division of the limbic system plays an essential role in the behavioural triad under consideration (MacLean, 1982a, b). Significantly, as Le Gros Clark \& Meyer (1950) have emphasized, there is no counterpart of this limbic subdivision in the reptilian brain. The other two subdivisions of the limbic system - namely, the amygdalar and septal subdivisions - had previously been shown to be primarily involved, respectively, in behaviour promoting self-preservation and procreation of the species.

Of profound epistemic import (MacLean, 1975), clinical findings in limbic (psychomotor) epilepsy have provided evidence that the limbic system derives subjective information in terms of emotional feelings that guide behaviour required for self-preservation and preservation of the species. One wonders whether the limbic system would ever have become such a 'solar plexus' with respect to emotional feelings if it had not been for the development in mammals of the family unit dependent on the nursing mother. Separation of the infant from the mother is calamitous. A condition that makes being a mammal so painful is separation from a sustaining member or members of a group. As mentioned above, the separation call may be the most basic mammalian vocalization. 
Our current findings in squirrel monkeys point to the preseptal cingulate cortex as a crucial locus for the spontaneous production of the separation call (MacLean, 1982b). Since the cingulate cortex has a high concentration of opiate receptors, it is notable that morphine eliminates the separation call, while the antagonist naloxone reinstates it (Newman et al. 1982).

The thalamocingulate division of the limbic system is intimately linked to the prefrontal neocortex which reaches its greatest development in human beings and which, among its other functions, appears to underlie altruistic sentiments. The mention of the prefrontal cortex, and its connection with the inferred family-related functions of the cingulate gyrus, provokes questions of the kind that evolutionary psychiatry may someday help to answer. Human beings, for example, are the only creatures known to shed tears with crying. Is it possible that the misting of the eyes so commonly experienced upon observing an altruistic act is in any way owing to a reciprocal innervation of mechanisms for parental rescue and for crying represented in the cingulate gyrus? Human beings and their antecedents are the only creatures known to have used fire. In the course of millions of years did there arise some connection between smoke and tears and activities surrounding fire, including ceremonies involved in disposing of departed loved ones?

PAULD. MACLEAN

\section{REFERENCES}

Clark, W. E. Le Gros \& Meyer, M. (1950). Anatomical relationships between the cerebral cortex and the hypothalamus. British Medical Bulletin 6, 341-345.

Darlington, C. D. (1978). A diagram of evolution. Nature 276, $447-452$.

Greenberg, N., MacLean, P. D., \& Ferguson, J. L. (1979). Role of paleostriatum in species-typical display behavior of the lizard Anolis carolinensis. Brain Research 172, 229-241.

Jacob, F. (1977). Evolution and tinkering. Science 196, 1161-1166.

Maclean, P. D. (1952). Some psychiatric implications of physiological studies on frontotemporal portion of limbic system (visceral brain). Electroencephalography and Clinical Neurophysiology 4, 407-418.

MacLean, P. D. (1970). The triune brain, emotion, and scientific bias. In The Neurosciences Second Siudy Program (ed. F. O. Schmitt), pp. 336-349. The Rockefeller University Press: New York.

Maclean, P. D. (1973). A Triune Concept of Brain and Behavior. University of Toronto Press: Toronto.

Maclean, P. D. (1975). On the evolution of three mentalities. ManEnvironment Systems 5, 213-224. Reprinted (1977) in New Dimen- sions in Psychiatry; A World View, Vol. 2 (ed. S. Arieti and G. Chrzanowski), pp. 305-382. John Wiley and Sons: New York. MacLean, P. D. (1978). Effects of lesions of globus pallidus on species-typical display behavior of squirrel monkeys. Brain Research 149, 175-196.

Maclean, P. D. (1980). Role of transhypothalamic pathways in social communication. In Handbook of the Hypothalamus (ed. P. Morgane and J. Panksepp), pp. 259-287. Marcel Dekker: New York.

MacLean, P. D. (1982a). On the origin and progressive evolution of the triune brain. In Primate Brain Evolution (ed. E. Armstrong and D. Falk), pp. 291-316. Plenum Press: New York.

MacLean, P. D. (1982b). The co-evolution of the brain and family. In Anthroquest, The L.S.B. Leakey Foundation News 24, 1 and 14-15. The L.S.B. Leakey Foundation: Pasadena, CA.

Murphy M. R., Maclean, P. D. \& Hamilton, S. C. (1981). Speciestypical behavior of hamsters deprived from birth of the neocortex. Science 213, 459-461.

Newman, J. D., Murphy, M. R. \& Harbaugh, C. R. (1982). Nalox one-reversible suppression of isolation call production after morphine injections in squirrel monkeys. Society for Neuroscience Abstracts 8, 940. 